\title{
THE EFFECTS OF RAMET DENSITY ON GROWTH AND BRANCHING OF SALVINIA MOLESTA
}

\author{
S.M. SOLANGAARACHCHI ${ }^{*}$ and R.P.K. DUSHYANTHA \\ Department of Botany, University of Kelaniya, Kelaniya.
}

(Received: 21 August 1995; accepted: 07 June 1996)

\begin{abstract}
Single ramets of the tropical, floating, freshwater, aquatic weed, Salvinia molesta at its tertiary stage were grown at initial densities of 16 plants, 80 plants and 160 plants per square meter, in a pond. Growth parameters were measured for each plant separately after 6 wks. Results showed that the number of nodes and leaves, the mean internodal length, the length of whole stolons, the dry weight of plants, the number of branches and the percentage branching decreased significantly $(p<0.05)$ with increasing initial density of ramets.
\end{abstract}

Key words: Ramets, Salvinia molesta.

\section{INTRODUCTION}

Plants are modular, in that they develop through iteration of morphological units termed modules. The iteration of these units, the leaf with its axillary bud and associated internode forms a branching structure, ${ }^{1}$ which depends on the branch angle, the internode lengths and the dynamics of the birth and death of meristems; and hence the arrangement of modules in space. Branching determines the fitness of an organism which depends on the number of descendants that a genet contributes to future generations. Although the branching pattern is genetically determined, its rules may change continually depending on the availability of resources. The response of modules to local environment was demonstrated by Noble,${ }^{2}$ who provided different local nutrient conditions to each module of a single rhizome of Carex arenaria L. Furthermore, light quality (reduced red to far-red ratio) and quantity (reduced light intensity) reduced the branching of Trifolium repens $\mathrm{L}^{3}$ Factors such as soil moisture, nutrient supply and the season also affect the branching of $T$. repens. ${ }^{4}$

The presence of both intraspecific and interspecific neighbours changes its local environment (e.g. availability of resources), affecting the growth of individuals in a population both at genet level and modular level. Thus higher densities (intra-specific neighbour effects) may increase the risk of mortality of genets, ${ }^{5}$ and on the other hand, they may alter birth and death rates of their modules such as leaves, branches, flowers, fruits, rootlets etc.

\footnotetext{
${ }^{*}$ Corresponding author.
} 
The response of plants to the density stress at modular level is expressed in the reduction in size frequently measured in terms of biomass. ${ }^{5-9}$ Reduced size however is mainly due to the effects at modular level and hence due to reduced branching. ${ }^{710,11}$ In clonal plants, density stress may influence modules more than genets.

The clonally spreading, floating aquatic fern Salvinia molesta Mitchell is a problematic weed in tropical fresh water bodies. The plant is sterile ${ }^{12}$ and therefore population increase depends on vegetative growth and branching. The plant develops branches from lateral buds, which arise in leaf axils on alternate sides of the stolon at successive nodes. Although there are three lateral buds in each axil it is the first rank bud that develops into branches under natural conditions, and the second and third rank buds develop in high nutrient conditions. ${ }^{13}$

The weed is being biologically controlled by a weevil Cyrtobagous salviniae Calder and Sands. ${ }^{14}$ In monitoring control programmes it is essential to know the behaviour of individuals and their parts under different environmental conditions such as availability of resources. The behaviour of individuals may then be interpreted in the context of the population. As the plant's fitness depends on vegetative propagation, studies on the growth and branching are of great importance. Reduced growth and branching due to the effects of damage to leaves and roots and increased branching due to severence of stolons have been reported..$^{15}$ The effect of density of plants on its morphological plasticity has also been studied. ${ }^{16}$ In thick growing mats of $S$. molesta (i.e. at the tertiary stage) density stress is unavoidable.

The results of experiments designed to study the effect of initial density of ramets (leaf pair with its root and axillary buds) at their tertiary stage $\mathrm{e}^{17}$ on growth and branching of $S$. molesta are reported here.

\section{METHODS AND MATERIALS}

The pond of $5 \times 3 \times 1 \mathrm{~m}$ in the botanical garden of the University of Kelaniya, was cleaned and layered with mud to $25 \mathrm{~cm}$ brought from a place where $S$. molesta grew densely, to which pond water was added upto $90 \mathrm{~cm}$ in height. This level was maintained throughout the experiment by adding pond water. Eighteen wooden frames (quadrats) of $25 \times 25 \mathrm{~cm}$ were placed afloat in the tank. The rootlets of all treatments share the same growth medium, although their above-water modules are partitioned by having the wooden frames.

Uniform (in age and size) single node cuttings (ramets) were selected from a healthy clone of $S$. molesta at its tertiary stage, and were used for different treatments. The following treatments were allocated to each frame using six 
replicate quadrats for each treatment. The lay-out of the experiment was a completely randomized design:

Treatment 1 (T1) - Control - Density - one ramet per quadrat (16 plants $\left./ \mathrm{m}^{2}\right)$

Treatment 2 (T2) - Density - Five ramets per quadrat $\left(80 \mathrm{plants} / \mathrm{m}^{2}\right)$

Treatment 3 (T3) - Density-Ten ramets per quadrat $\left(160 \mathrm{plants} / \mathrm{m}^{2}\right)$

Temperature of the water was $28 \pm 1^{\circ} \mathrm{C}$ during this period.

After six weeks of growth each individual plant was destructively harvested and number of nodes and leaves on main and primary stolons (stolons arising from main stolon), number of branches on the main stolon, length of main and primary stolons, and the mean internodal length of the main stolon were measured. Five randomly selected plants from T3 treatment quadrats were taken for measurements. Then the plants were washed carefully and the leaves; roots and stolons were separated in each plant and were placed in separate paper bags and oven dried at $70^{\circ} \mathrm{C}$, and the final constant weights were recorded. The percentage branching was then calculated.

The analysis of variance was carried out on the MINITAB data analysis package on a Commodore PC 10 III. Multiple comparison tests were carried out for the comparison between three treatments using Sheffe's method. ${ }^{18}$. Each experiment was carried out three times and the results were similar. Hence the results of the third experiment are reported here.

\section{RESULTS}

Table 1 shows the overall values for the parameters for each individual in each treatment. The number of nodes, leaves, the length of stolons, the internode length, the number of branches, percentage branching and dry weights of leaves, roots and stolons were highest in the control, and decreased with increasing density of individuals. The number of nodes on the main stolon of each individual plant decreased significantly $(\mathrm{p}<0.05)$ by $12 \%$ and $18 \%$ in the intermediate (T2) and in the highest (T3) density treatments respectively. The effect on the number of nodes on primary stolons was greater than that on main stolons. The highest number of nodes was found in the control treatment, whilst it was reduced by $69 \%$ and $98 \%$ in $\mathrm{T} 2$ and $\mathrm{T} 3$ treatments respectively. The number of leaves on the main stolons were reduced to $89 \%$ and $83 \%$ of the control in T2 and T3 treatments respectively whilst the reductions were $68 \%$ and $98 \%$ in T2 and T3 treatments respectively on primary stolons.

Control plants had the longest main stolons, and in the other two density treatments, the length decreased by $18 \%$ and $25 \%$ respectively. The effect was greater in the primary stolons than that found in the main stolon. These reductions were $67 \%$ and $98 \%$ in $\mathrm{T} 2$ and $\mathrm{T} 3$ treatments respectively. The mean internode length was also significantly $(\mathrm{p}<0.05)$ decreased by $30 \%$ and $35 \%$ of 
the control in the intermediate and highest densities respectively. Number of branches on the main stolon was the highest in the control plants and it has reduced by $56 \%$ and $83 \%$ in the $\mathrm{T} 2$ and $\mathrm{T} 3$ treatments respectively.

Table 1: The effect of density on branching of S. molesta

Treatments

Variable

$\mathrm{T} 1$

$\mathrm{T} 2$

T3

Number of nodes

Main stolon

Primary stolons

Number of leaves

Main stolon

Primary stolon

Length

Main stolon (cm)

Primary stolons $(\mathrm{cm})$

Mean Internode length $(\mathrm{cm})$

Number of branches

Main stolon

Percentage branching
$12.83 \pm 0.30 \mathrm{a}$

$24.00 \pm 0.96 \mathrm{a}$

$11.23 \pm 0.08 \mathrm{~b}$

$07.50 \pm 0.32 b$

$10.50 \pm 0.06 \mathrm{c}$

$00.50 \pm 0.02 \mathrm{c}$
$25.33 \pm 0.61 \mathrm{a}$

$47.33 \pm 2.02 \mathrm{a}$
$22.46 \pm 0.14 \mathrm{~b}$

$15.10 \pm 0.64 b$
$21.06 \pm 0.12 \mathrm{c}$

$01.00 \pm 0.05 c$
$11.16 \pm 0.21 \mathrm{a}$

$17.30 \pm 1.12 \mathrm{a}$

$00.91 \pm 0.03 a$
$09.15 \pm 0.16 \mathrm{a}$

$05.76 \pm 0.29 \mathrm{~b}$

$08.32 \pm 0.16 \mathrm{~b}$

$00.37 \pm 0.03 \mathrm{c}$

$00.64 \pm 0.01 b$

$00.59 \pm 0.00 \mathrm{bc}$

Dry weight (g)

Leaves

Roots

Stolons
$03.16 \pm 0.31 \mathrm{a}$

$25.28 \pm 2.21 \mathrm{a}$
$01.40 \pm 0.04 \mathrm{~b}$

$12.51 \pm 0.38 \mathrm{~b}$
$00.55 \pm 0.02 \mathrm{c}$

$05.48 \pm 0.22 \mathrm{c}$

$$
\begin{aligned}
& 00.28 \pm 0.02 a \\
& 00.29 \pm 0.02 a \\
& 00.04 \pm 0.00 a
\end{aligned}
$$$$
00.21 \pm 0.00 \mathrm{~b}
$$$$
00.16 \pm 0.00 c
$$$$
00.19 \pm 0.00 \mathrm{~b}
$$$$
00.14 \pm 0.00 \mathrm{c}
$$

$00.02 \pm 0.00 \mathrm{a}$

$00.20 \pm 0.00 \mathrm{a}$

Each value is an overall mean for six replicate quadrats. T1 - one ramet per quadrat (control), T2 five ramets per quadrat, $\mathrm{T} 3$ - ten ramets per quadrat. Mean \pm se sharing the same letter within each row do not differ significantly $(p>0.05)$. 
The highest percentage branching was found in the control plants and there was a gradual yet, significant $(p<0.05)$ decrease with increasing density of individuals, and the reductions were $50 \%$ and $78 \%$ in T2 and T3 treatments respectively. The density treatments affected the dry weights of leaves and roots significantly $(\mathrm{p}<0.05)$. The dry weights were highest in the control treatment, whilst there was a gradual decrease with increasing density. Dry weights of leaves reduced to $75 \%$ and $57 \%$, roots reduced to $66 \%$ and $48 \%$ whilst stolons reduced to $50 \%$ in both $\mathrm{T} 2$ and $\mathrm{T} 3$ treatments.

\section{DISCUSSION}

The results show that plants grown at higher densities were less branched and smaller in size. The observed results are supported by similar observations made by various authors for erect plants with single stems or stages of plants with single stems, e.g. Helianthus annus L., ${ }^{11}$ Spergula arvensis L. ${ }^{10}$ Trifolium subterraneum $\mathrm{L} .{ }^{19}$ Clonally spreading plants also have shown less branching at high densities, e.g. at high densities the rate of tiller formation decreased in Lolium perenne L. ${ }^{9}$ Similar results have been reported for Trifolium repens. ${ }^{20,21}$ Solangaarachchi and Harper ${ }^{22}$ have also shown that in T. repens plants, when grown close to each other branching decreased on interfering sides. At higher densities, plants and their parts compete for the same limited resources (nutrients, water, light and space) available in their immediate environment and this probably influenced the growth and branching of individual plants of S. molesta at higher densities.

At higher densities plants with erect stems elongate their stems (via internode length) which helps keep the leaves exposed to better light. In the present study mean internode length and the length of primary but not main stolons decreased significantly at higher densities. This is probably because stolons grow horizontally and an increase in their extension rate does not place the leaves higher in the canopy. Branching or their further development can continue until all the space is occupied by Resource Depletion Zones (RDZs). ${ }^{23}$ Thus branching may change according to the availability of resources. Similar results have been found for fungal colonies (J.L. Harper personal communication).

The nutrient content in water is probably uniformly distributed and therefore even at higher densities, nutrient limitation may not be a significant factor. Thus in the present experiment reduced branching of each individual at higher densities could have been due to the availability of less space, which could have influenced the light quantity as well as light quality. At higher densities bud sites are naturally shaded by leaves of individuals, ${ }^{24}$ whereas at lower densities the natural shading occurs to a less extent. Thus bud sites may not have been well exposed to light at higher densities, and further development of them may have been inhibited, e.g. reduced growth and branching at low light intensities have been reported for Trifolium repens. ${ }^{3,25}$ 


\section{References}

1. Harper J. L. (1981). The concept of population in modular organisms. In: Theoretical ecology, (Ed. R. M. May), pp. 53-77. Blackwell Scientific publications.

2. Noble J.C. (1976). The population biology of rhizomatous plants. Ph.D. Thesis, University of Wales, U.K.

3. Solangaarachchi S.M. \& Harper J.L. (1987). The effect of canopy filtered light on the growth of white clover (Trifolium repens). Oecologia (Berlin) 72: 372-378.

4. Chapman D.F. (1983). Growth and demography of Trifolium repens stolon in grazed pastures. Journal of Applied Ecology 20: 597-608.

5. Yoda K., Kira T., Ogawa H. \& Hozumi K. (1963). Self thinning in overcrowded pure stands under cultivated and natural conditions. Journal of Biology Osaka City University 14: 107-129.

6. Clatworthy J.N. (1960): Studies on the nature of competition between closely related species. D. Phil. Thesis, University of Oxford.

7. Harper J.L. (1961). Approaches to the study of plant competition. In: Mechanisms in biological competition (Ed. F.L. Mithorpe). Proceedings of the Symposium of the Society of Experimental Biology 15: 1-39.

8. Ross M.A. \& Harper J.L. (1972). Occupation of biological space during seedling establishment. Journal of Ecology 66: 77-88.

9. Kays S. \& Harper J.L. (1974). The regulation of plant and tiller density in a grass-sward. Journal of Ecology 62: 97-105.

10. New J. (1961). Biological flora of the British. Isles: Spergula arvensis. Journal of Ecology 49: 205-215.

11. Kobayashi S. (1975). Growth analysis of plants as an assemblage of internodal segments: a case of sunflower plants in pure stand. Japanese Journal of Ecology 25: 61-70.

12. Loyal D.S. \& Grewal R.K. (1966). Cytological study on sterility in Salvinia auriculata Aublet with a bearing on its reproductive mechanism. Cytologia 31: $330-338$. 
13. Room P.M. (1984). Plant architecture and how biological control agents affect the dynamics of weeds. Proceedings of the VIth International Symposium of Biological Control of Weeds. (Ed. E.S. Delfosse), pp. 89-102. Vancouver, Canada.

14. Room P.M., Harley K.L.S., Forno I.W. \& Sanda D.P. (1981). Successful biological control of the floating weed Salvinia. Nature (Lond.) 294: 78-80.

15. Solangaarachchi S.M. \& Dushyantha R.P.K. (1991). Growth and branching of damaged Salvinia molesta. Journal of National Science Council of Sri Lanka 22(3): 271-278.

16. Solangaarachchi S.M. \& Hapuarachchi H.T. (1995). Intraspecific neighbour effects on the growth and morphological plasticity of Salvinia molesta. Journal of National Science Council of Sri Lanka 23(1): 31-38.

17. Mitchell D.S. (1970). Autoecological studies of Salvinia auriculata Aubl. Ph.D. Thesis, Universityof London.

18. Zar J.H. (1984). Biostatistical analysis. 2nd edition. Prentice-Hall International Inc., London.

19. Donald C.M. (1951). Competition among pasture plants. I. Intra-specific competition among annual pasture plants. Australian Journal of Agricultural Research 2: 355-376.

20. Erith A.G. (1924). Whiteclover(Trifolium repens L.). A monograph. Duckworth, London.

21. Harvey H.J. (1979). The regulation of vegetative reproduction. Ph.D. Thesis, University of Wales.

22. Solangaarachchi S.M. \& Harper J.L. (1989). The growth and asymmetry of neighbouring plants of white clover (Trifolium repens L.) Oecologia 78: 208-213.

23. Begon M., Harper J.L. \& Townsend C.R. (1990). Ecology. 2nd edition. Blackwell Scientific Publications, London.

24. Trautner J.L. \& Gibson P.B. (1966). Fate of white clover axillary buds at five intensities of sun-light. Agronomy Journal 58: 557-559.

25. Black J.N. (1960). The significance of petiole length, leaf area and light interception in competition between strains of subterranean clover (Trifolium subterraneum L.) growth in swards. Australian Journal of Agricultural Research 11: 277-291. 